\title{
Heritability of upper airway dimensions derived using acoustic pharyngometry
}

\author{
S.R. Patel*,\#, J.M. Frame" ${ }^{\#}$ E.K. Larkin" and S. Redline ${ }^{*, \#}$
}

ABSTRACT: Acoustic pharyngometry represents a simple, quick noninvasive method of measuring upper airway dimensions, which are predictive of sleep apnoea risk. The aim of the present study was to assess the genetic basis of upper airway size as determined using pharyngometry.

Participants in the Cleveland Family Study aged $>14$ yrs underwent three acoustic pharyngometric measurements. Variance component models adjusted for age and sex were used to estimate the heritability of pharyngometry-derived airway measures.

A total of 568 out of $655(87 \%)$ subjects provided pharyngometric curves of sufficient quality. Although African-Americans tended to show narrower airways compared with white subjects, heritability patterns were similar in these two groups. The minimum cross-sectional area exhibited a heritability of 0.34 in white subjects and 0.39 in African-Americans, suggesting that $30-40 \%$ of the total variance in this measure is explained by shared familial factors. Estimates were unchanged after adjustment for body mass index or neck circumference. In contrast, oropharyngeal length did not show significant heritability in either ethnic group.

The minimum cross-sectional area of the oropharynx is a highly heritable trait, suggesting the presence of an underlying genetic basis. These findings demonstrate the potential utility of acoustic pharyngometry in dissecting the genetic basis of sleep apnoea.

KEYWORDS: Genetic epidemiology, heritability, oropharynx, pharyngometry, sleep apnoea, upper airway

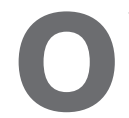
bstructive sleep apnoea (OSA) has been shown to have an important familial component, suggesting the presence of a genetic basis for this disorder [1-3]. The pathways by which genetic polymorphisms might influence OSA susceptibility are not completely clear, but upper airway anatomy probably represents an important mechanism. Numerous studies have identified specific anatomical features that predispose to OSA [4-7]. Many of the bony craniofacial risk factors have been shown to be strongly heritable $[8,9]$. More recently, using magnetic resonance imaging (MRI), soft tissue structures in the airway have also been shown to demonstrate familial correlation [10]. Unfortunately, such elegant imaging is both time- and cost-intensive, limiting the use of this modality to the identification of susceptibility genes in large populations; in addition, it cannot be performed on extremely obese individuals. Acoustic pharyngometry represents a relatively simple and quick method of assessing upper airway dimensions, which has been shown to predict OSA status [11, 12]. In the present study, the heritability $\left(h^{2}\right)$ of upper airway measurements derived from acoustic pharyngometry were assessed in participants in the Cleveland Family Study in order to estimate the potential utility of this tool for use in large-scale phenotyping efforts.

\section{METHODS}

\section{Subjects}

The Cleveland Family Study is a longitudinal family-based epidemiological cohort designed to study the genetics of OSA. Details of the recruitment of this cohort have been described laboratory-confirmed diagnosis of OSA and at least two first-degree relatives available for study were recruited along with family members. A subset of 725 individuals was selected for detailed phenotyping based on expected genetic informativity by choosing pedigrees in which siblings showed extremes (either high or low) of apnoea/hypopnoea index (AHI). A more detailed explanation of the selection scheme has been published previously [2]. Owing to potential confounding effects due to adenotonsillar hypertrophy in young children, only participants previously $[1,13]$. Briefly, index probands with a

\section{AFFILIATIONS}

*Division of Pulmonary, Critical Care and Sleep Medicine, University Hospitals Case Medical Center and Case Western Reserve University, and

\#Center for Clinical Investigation, Case Western Reserve University, Cleveland, $\mathrm{OH}$, USA.

CORRESPONDENCE

S.R. Patel

11400 Euclid Avenue

Room 290-D

Cleveland

OH 44106

USA

Fax: 12168446265

E-mail: srp20@case.edu

Received:

February 262008

Accepted after revision:

June 092008

SUPPORT STATEMENT

This study was supported by National Institutes of Health (Bethesda, MD, USA) grants HL081385, HL046380 and KL2 RR024990.

STATEMENT OF INTEREST None declared. 
aged $>14$ yrs were included in the present analysis. The protocol was approved by the University Hospitals Case Medical Center institutional review committee (University Hospitals Case Medical Center, Cleveland, $\mathrm{OH}, \mathrm{USA}$ ) and all participants provided written informed consent.

\section{Phenotype collection}

Measurements of height, weight and neck circumference were made in duplicate and averaged. Body mass index (BMI) was calculated as the ratio of weight to height squared. Attended overnight laboratory polysomnography (Compumedics, Abbotsford, Australia) was performed using both an oronasal thermocouple and a nasal pressure cannula to assess airflow. Apnoeas and hypopnoeas were defined using Sleep Heart Health Study criteria, modified to include consideration of the nasal pressure signal [14]. The AHI was computed by dividing the number of respiratory events by total sleep time.

\section{Acoustic pharyngometry}

Pharyngometry (Eccovision; Hood Laboratories, Pembroke, MA, USA) was performed with the subject seated comfortably with the head in the Frankfort horizontal plane and breathing orally through a rubber mouthpiece that included a midline bridge to stabilise tongue position on the evening prior to polysomnography. Each measurement consisted of a plot of cross-sectional area (CSA) as a function of distance from the mouth (fig. 1). An initial plot was performed with the subject breathing nasally. This was followed by three traces obtained with the subject breathing orally at functional residual capacity. Traces were scored as being of poor, adequate or high quality according to clarity in identifying landmarks. Subjects with at least two adequate or high-quality traces were included in the present analysis.

The oropharyngeal segment was defined as the region between the proximal minimum and distal minimum CSA. These points correspond anatomically to the oropharyngeal junction and epiglottis. Eight dimensions were obtained from each curve, and averaged over the two or three curves of sufficient

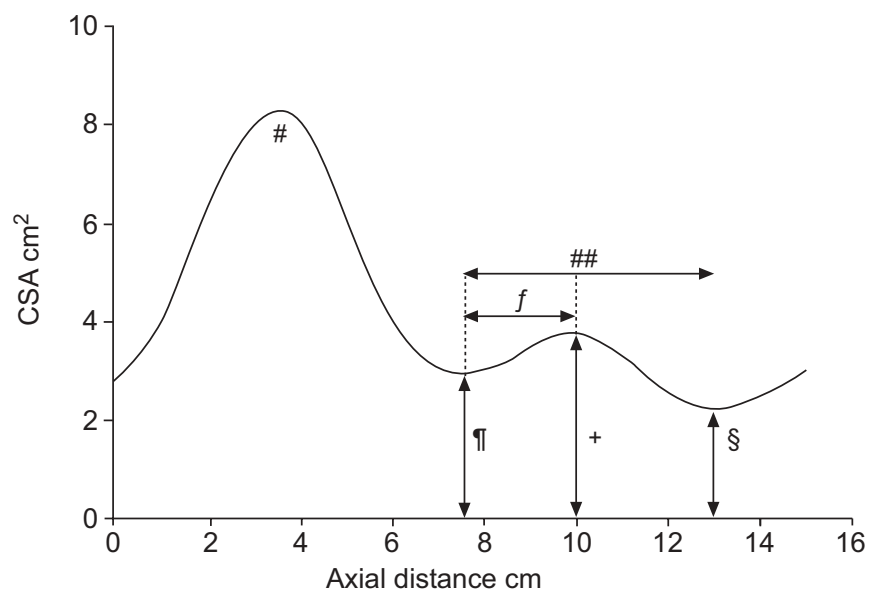

FIGURE 1. Sample schematic showing acoustic pharyngometric trace variables. The mean cross-sectional area (CSA) was obtained by averaging the proximal (") and distal minima ( $\left(^{\S}\right)$. The volume is the product of the mean CSA and oropharyngeal length $(\#)$. The relative maximum location is the ratio of maximum location $\left(^{f}\right)$ to oropharyngeal length. ${ }^{*}$ : oral cavity; ${ }^{+}$: maximum CSA. quality: five cross-sectional dimensions (proximal minimum CSA, distal minimum CSA, overall minimum CSA, maximum CSA and mean CSA), and three axial dimensions (oropharyngeal segment length, relative position of the maximum CSA over the segment length and segment volume). Segment volume was computed as the product of mean CSA and segment length.

\section{Pharyngometric validation}

In a subgroup of 10 individuals (six females and four males) with a wide range of AHI (2-68 events $\left.\cdot h^{-1}\right)$, acoustic pharyngometry was performed immediately prior to MRI of the upper airway. Axial images were obtained through use of a 1.5-T Siemens Espree system (Siemens, Erlangen, Germany) using a two-dimensional spin echo sequence (repetition time $400 \mathrm{~ms}$; echo time $12 \mathrm{~ms}$ ) and $5 \mathrm{~mm}$ slice thickness, with the subject supine, awake and breathing through the pharyngometric mouthpiece. The air-tissue boundary was manually defined by a technician blinded to pharyngometric measurements, and the University of Texas Health Science Center at San Antonio (UTHSCSA) Image Tool version 2.0 (UTHSCSA, San Antonio, TX, USA) was used to compute the CSA in each slice. The proximal minimum CSA obtained by MRI while supine was substantially smaller than that obtained by pharyngometry while seated $\left(1.09\right.$ versus $\left.2.28 \mathrm{~cm}^{2}\right)$. However, the Spearman correlation coefficient between the two measures was strong $(\mathrm{r}=0.75 ; \mathrm{p}=0.01)$.

\section{Statistical analysis}

Differences between white subjects and African-Americans were assessed using Chi-squared and unpaired t-tests. Estimates of $\mathrm{h}^{2}$ were computed using the maximumlikelihood-based variance-components approach implemented in the statistical genetics software package, Sequential Oligogenic Linkage Analysis Routines (SOLAR) version 4.0.7 [15]. All models included age and sex as covariates and conditioned on the proband data in order to account for potential ascertainment bias. The $\mathrm{h}^{2}$ was computed as the ratio of the genetic variance to the sum of the genetic and environmental variances, and represents the proportion of the total variance in a trait (after adjusting for covariate effects) that is explained by additive genetic effects. Additional analyses were performed including BMI and neck circumference as covariates in order to estimate the $h^{2}$ of upper airway measures independent of these potential contributing variables. Since there was potential for different patterns of genetic transmission across races, all analyses were performed separately in white subjects and African-Americans.

\section{RESULTS}

\section{Subject characteristics}

Of 655 subjects aged $>14$ yrs who underwent pharyngometry, 568 (87\%) yielded curves that met the minimum quality criteria used in the present analysis. The participant characteristics for each racial group are presented in table 1 . In general, the two groups were similar in weight and OSA severity. However, the African-American cohort tended to show a narrower airway, as evidenced by the smaller mean and minimal pharyngeal CSA. 


\begin{tabular}{|c|c|c|c|}
\hline & $\begin{array}{l}\text { White } \\
\text { subjects }\end{array}$ & African-Americans & $p$-value \\
\hline Subjects $n$ & 229 & 339 & \\
\hline Males & $102(44.5)$ & $140(41.3)$ & 0.44 \\
\hline Age yrs & $42.1 \pm 19.2$ & $38.2 \pm 18.9$ & 0.02 \\
\hline $\mathrm{BMI} \mathbf{k g} \cdot \mathrm{m}^{-2}$ & $32.0 \pm 9.3$ & $32.4 \pm 9.9$ & 0.62 \\
\hline Neck circumference $\mathrm{cm}$ & $38.4 \pm 5.2$ & $38.3 \pm 5.2$ & 0.67 \\
\hline AHI events $\cdot h^{-1}$ & $16.6 \pm 24.6$ & $15.5 \pm 24.1$ & 0.60 \\
\hline \multicolumn{4}{|l|}{ 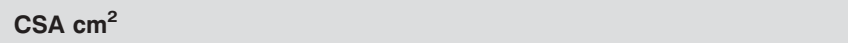 } \\
\hline Maximum & $3.24 \pm 0.94$ & $2.84 \pm 0.89$ & $<0.001$ \\
\hline Mean & $2.65 \pm 0.67$ & $2.34 \pm 0.68$ & $<0.001$ \\
\hline Minimum & $1.93 \pm 0.57$ & $1.75 \pm 0.55$ & $<0.001$ \\
\hline Proximal minimum & $2.14 \pm 0.71$ & $1.86 \pm 0.64$ & $<0.001$ \\
\hline Distal minimum & $2.56 \pm 0.81$ & $2.38 \pm 0.79$ & 0.008 \\
\hline Relative maximum location & $0.57 \pm 0.24$ & $0.63 \pm 0.22$ & 0.004 \\
\hline Length $\mathrm{cm}$ & $4.93 \pm 1.27$ & $4.85 \pm 1.30$ & 0.48 \\
\hline Volume $\mathrm{cm}^{3}$ & $13.31 \pm 5.57$ & $11.57 \pm 5.21$ & $<0.001$ \\
\hline
\end{tabular}

Data are presented as $\mathrm{n}(\%)$ and mean $\pm \mathrm{SD}$, unless otherwise indicated. BMI: body mass index; AHI: apnoea/hypopnoea index; CSA: cross-sectional area.

\section{Heritability analyses}

Six subjects were excluded from the genetic analysis as they had no family members with pharyngometric results. The remaining subjects came from 131 families (224 individuals in 53 white families and 338 individuals in 78 African-American families). Among white subjects, the distal minimum CSA and the overall minimum CSA were the most heritable pharyngometric measures, with $h^{2}$ of $0.37 \pm 0.19$ and $0.34 \pm 0.15$, respectively (table 2 ). The proximal minimum CSA also showed evidence of a genetic basis $\left(h^{2} 0.24 \pm 0.13\right)$, whereas the $\mathrm{h}^{2}$ of the mean and maximum CSA was much lower.

In the African-American sample, the distal minimum CSA and overall minimum CSA were also the most heritable pharyngometric measures, with $h^{2}$ of $0.37 \pm 0.13$ and $0.39 \pm 0.13$, respectively (table 3 ). In contrast to the white cohort, the other CSA measures, including mean and maximum oropharyngeal
CSA, also showed evidence of a genetic basis, with $\mathrm{h}^{2}$ in the range $0.20-0.30$.

Adjustment for BMI or neck circumference had minimal effect on $\mathrm{h}^{2}$ estimates in either ethnic group. In contrast to the substantial $\mathrm{h}^{2}$ found for airway CSA measures, little evidence was found for a genetic basis for axial measures. Oropharyngeal length, relative location of the maximal CSA and oropharyngeal airway volume were not heritable in either white subjects or African-Americans.

Secondary analyses were performed limited to individuals for whom at least two curves met the highest quality rating. In general, $\mathrm{h}^{2}$ were greater in this subgroup of 224 individuals. For example, the $\mathrm{h}^{2}$ of the minimum CSA was $0.56 \pm 0.19$ $(p=0.002)$ in white subjects and $0.44 \pm 0.18 \quad(p=0.004)$ in African-Americans.

\section{DISCUSSION}

The present results suggest that upper airway dimensions derived via acoustic pharyngometry demonstrate substantial intra-familial correlation. For the minimum oropharyngeal CSA, $\mathrm{h}^{2}$ was $0.30-0.40$, implying that $\geqslant 30-40 \%$ of the overall variance in this measure can be explained by intra-familial factors, such as shared genetic polymorphisms. Higher $h^{2}$ estimates are obtained when only the highest-quality curves are considered. Findings were independent of BMI or neck circumference, suggesting that the relevant genes act independently of overall obesity. A previous study by MATHUR and DOUGLAS [16] demonstrated that the airways of relatives of apnoeics, as assessed by pharyngometry, were narrower than those of controls, although that work did not quantify the strength of the familial correlation. Since studies have demonstrated that a small minimum oropharyngeal CSA predicts the presence of OSA [12,17], genes that influence the minimum CSA are also likely to influence OSA status.

The $\mathrm{h}^{2}$ of the minimum CSA is of similar magnitude to that of the AHI, which has been estimated to be $0.32-0.37$ in several studies $[2,3,18]$. An important difference in these two apnoearelated traits is that there are probably fewer genes responsible for the overall genetic effect on minimum CSA, such that the locus-specific $\mathrm{h}^{2}$ of the genes with strongest effect is greater for minimum CSA. In addition to genes influencing upper airway

TABLE 2 Heritability $\left(h^{2}\right)$ of pharyngometric measures in white subjects by adjustments

\begin{tabular}{|c|c|c|c|c|c|c|}
\hline & \multicolumn{2}{|c|}{ Age/sex } & \multicolumn{2}{|c|}{ Age/sex/BMI } & \multicolumn{2}{|c|}{ Age/sex/neck circ. } \\
\hline Maximum & 0.06 & 0.31 & 0.04 & 0.41 & 0.08 & 0.27 \\
\hline Mean & 0.18 & 0.08 & 0.15 & 0.19 & 0.19 & 0.08 \\
\hline Minimum & 0.34 & 0.004 & 0.32 & 0.01 & 0.34 & 0.004 \\
\hline Relative maximum location & 0.06 & 0.36 & 0.04 & 0.40 & 0.03 & 0.43 \\
\hline Length & 0.00 & 0.50 & 0.00 & 0.50 & 0.00 & 0.50 \\
\hline Volume & 0.00 & 0.50 & 0.00 & 0.50 & 0.00 & 0.50 \\
\hline
\end{tabular}

BMI: body mass index; circ.: circumference; CSA: cross-sectional area. 
TABLE 3 Heritability $\left(h^{2}\right)$ of pharyngometric measures in African-Americans by adjustments

\begin{tabular}{|c|c|c|c|c|c|c|}
\hline & \multicolumn{2}{|c|}{ Age/sex } & \multicolumn{2}{|c|}{ Age/sex/BMI } & \multicolumn{2}{|c|}{ Age/sex/neck circ. } \\
\hline \multicolumn{7}{|l|}{ CSA } \\
\hline Maximum & 0.21 & 0.03 & 0.19 & 0.04 & 0.19 & 0.04 \\
\hline Mean & 0.26 & 0.01 & 0.24 & 0.01 & 0.25 & 0.01 \\
\hline Minimum & 0.39 & $<0.001$ & 0.37 & $<0.001$ & 0.39 & $<0.001$ \\
\hline Relative maximum location & 0.00 & 0.50 & 0.01 & 0.46 & 0.02 & 0.43 \\
\hline Length & 0.17 & 0.08 & 0.16 & 0.09 & 0.17 & 0.08 \\
\hline Volume & 0.08 & 0.16 & 0.06 & 0.26 & 0.07 & 0.23 \\
\hline
\end{tabular}

anatomy, the AHI is probably influenced by genes that regulate such varied phenotypes as obesity, ventilatory control, arousal threshold and loop gain. Genetic analyses of an upper airway phenotype may provide insight into one of the causal pathways patho-aetiologically related to OSA. Because of its ease of use, acoustic pharyngometry is ideally suited to the study of the thousands of subjects required for epidemiological studies aimed at dissecting the genetics of OSA.

An additional finding of the present study is the similar inheritance patterns between white subjects and AfricanAmericans, despite there being a smaller airway in AfricanAmericans. In both groups, the distal minimum CSA and overall minimum CSA were the most heritable measures, followed by the proximal minimum CSA. Minimal CSA was also the pharyngometric measure found to best discriminate between children with and without OSA [19]. These data also suggest that cross-sectional airway dimensions exhibit a greater genetic basis than axial dimensions. This may, in part, be due to greater measurement error in estimating airway length than CSA using acoustic pharyngometry. However, similar results were found using MRI in the work of SCHWAB et al. [10]. In that study, the greater $h^{2}$ of cross-sectional airway measures compared to volumetric measures suggested that airway length may have less of a genetic basis than other dimensions. Furthermore, fluid dynamic theory would argue that OSA pathogenesis is much more sensitive to changes in the crosssectional compared to the axial dimensions of the upper airway.

Another notable finding is the increase in $\mathrm{h}^{2}$ associated with limiting the analysis to those subjects with high-quality curves. The $\mathrm{h}^{2}$ of minimum CSA increased to $0.45-0.55$ in this subset, suggesting that measurement error may represent a portion of the nongenetic variance. It is worth noting that these values are similar to the $h^{2}$ of 0.46 reported by SCHWAB et al. [10] for minimum CSA using MRI. Lower-quality curves may result from challenges in collecting such measurements in some individuals due to swallowing or tongue placement during the manoeuvre. These findings highlight the importance of using careful standardised methodology for performing pharyngometry, and the need to further improve methodology for stabilising the tongue during test manoeuvres.
The overall validity of pharyngometry for assessment of pharyngeal CSA is supported by both prior work showing its ability to discriminate between subjects with and without OSA $[12,17]$ and the high correlation observed between minimum CSA obtained pharyngometrically with measurements obtained by MRI. However, a limitation of acoustic pharyngometry is that it does not provide information about specific tissue structures, such as the genioglossus muscle and parapharyngeal fat pads. If airway dimensions are defined secondarily by the residual volume remaining after defining the structure of the bones, muscles, fat and connective tissue in the neck, it would be expected that the $h^{2}$ of the volumes of these structures would be greater than that of the airway lumen. However, the $\mathrm{h}^{2}$ of airway measurements in the study by SCHWAB et al. [10] were greater than those for individual soft tissue structures. This suggests the possibility that genetic mechanisms might primarily define airway dimensions and that they secondarily limit the size of surrounding structures. Alternatively, the various structures surrounding the airway may be influenced by the same set of genes, such that the power for detecting the effects of these genes is increased by considering a summary measure, such as the joint effects on the airway lumen, as opposed to the magnitude of each individual structure.

Several limitations of acoustic pharyngometry should be noted. First, it cannot distinguish airway narrowing caused by impingement of surrounding tissues from reduced neuromuscular compensation. Thus, the possibility that the genetic basis observed for airway calibre occurs due to genes that act to modulate neural control of upper airway musculature rather than genes that influence anatomical structure cannot be excluded. Secondly, acoustic pharyngometry provides no information regarding nasopharyngeal dimensions, which may be a relevant region for collapse in many patients with OSA. However, previous studies have demonstrated that oropharyngeal dimensions, as measured by acoustic pharyngometry, predict OSA status; thus, the present authors believe that the current findings are relevant to OSA gene discovery. Finally, the pharyngometric measurements used in the present study were obtained with subjects seated rather than supine. Although small, the validation study suggested that seated 
pharyngometric measurements correlate with supine MRI measurements. Previous studies have found that the magnitude of decrease in airway luminal volume upon going from the seated to supine position varies by sex [20]. As a result, the present results using seated measurements may represent a biased estimate of the $\mathrm{h}^{2}$ of supine airway dimensions.

In summary, the present study demonstrates the utility of acoustic pharyngometry in studying the genetic basis of variability in upper airway shape by demonstrating the substantial heritability of pharyngometrically derived airway measures. Although pharyngometry clearly cannot provide detail regarding specific structures that impinge upon the airway, as can be obtained using magnetic resonance imaging or other technologies, pharyngometry is relatively low-cost, minimally burdensome and noninvasive, and is therefore amenable for use in the large-scale studies required for the discovery of genes for obstructive sleep apnoea-related traits.

\section{REFERENCES}

1 Redline S, Tishler PV, Tosteson TD, et al. The familial aggregation of obstructive sleep apnea. Am J Respir Crit Care Med 1995; 151: 682-687.

2 Palmer LJ, Buxbaum SG, Larkin E, et al. A whole-genome scan for obstructive sleep apnea and obesity. Am J Hum Genet 2003; 72: 340-350.

3 Palmer LJ, Buxbaum SG, Larkin EK, et al. Whole genome scan for obstructive sleep apnea and obesity in African-American families. Am J Respir Crit Care Med 2004; 169: 1314-1321.

4 Cakirer B, Hans MG, Graham G, Aylor J, Tishler PV, Redline $S$. The relationship between craniofacial morphology and obstructive sleep apnea in Whites and in AfricanAmericans. Am J Respir Crit Care Med 2001; 163: 947-950.

5 Jamieson A, Guilleminault C, Partinen M, Quera-Salva MA. Obstructive sleep apneic patients have craniomandibular abnormalities. Sleep 1986; 9: 469-477.

6 Lowe AA, Santamaria JD, Fleetham JA, Price C. Facial morphology and obstructive sleep apnea. Am J Orthod Dentofacial Orthop 1986; 90: 484-491.

7 Schwab RJ, Pasirstein M, Pierson R, et al. Identification of upper airway anatomic risk factors for obstructive sleep apnea with volumetric magnetic resonance imaging. Am J Respir Crit Care Med 2003; 168: 522-530.

8 Osborne RH, De George FV. Genetic Basis of Morphologic Variation: an Evaluation and Application of the Twin
Study Method. Cambridge, Harvard University Press, 1959.

9 Nance WE, Nakata M, Paul TD, Yu PI. The use of twin studies in the analysis of phenotypic traits in man. In: Janerich DT., Skalko RG., Porter IH., eds. Congenital Defects: New Directions in Research. New York, Academic Press, 1974; pp. 23-49.

10 Schwab RJ, Pasirstein M, Kaplan L, et al. Family aggregation of upper airway soft tissue structures in normal subjects and patients with sleep apnea. Am J Respir Crit Care Med 2006; 173: 453-463.

11 Hoffstein V, Zamel N, Phillipson EA. Lung volume dependence of pharyngeal cross-sectional area in patients with obstructive sleep apnea. Am Rev Respir Dis 1984; 130 175-178.

12 Martin SE, Marshall I, Douglas NJ. The effect of posture on airway caliber with the sleep-apnea/hypopnea syndrome. Am J Respir Crit Care Med 1995; 152: 721-724.

13 Buxbaum SG, Elston RC, Tishler PV, Redline S. Genetics of the apnea hypopnea index in Caucasians and African Americans: I. Segregation analysis. Genet Epidemiol 2002; 22: 243-253.

14 Redline S, Sanders MH, Lind BK, et al. Methods for obtaining and analyzing unattended polysomnography data for a multicenter study. Sleep Heart Health Research Group. Sleep 1998; 21: 759-767.

15 Almasy L, Blangero J. Multipoint quantitative-trait linkage analysis in general pedigrees. Am J Hum Genet 1998; 62: 1198-1211.

16 Mathur R, Douglas NJ. Family studies in patients with the sleep apnea-hypopnea syndrome. Ann Intern Med 1995; 122: 174-178.

17 Monahan K, Kirchner HL, Redline S. Oropharyngeal dimensions in adults: effect of ethnicity, gender, and sleep apnea. J Clin Sleep Med 2005; 1: 257-263.

18 Carmelli D, Colrain IM, Swan GE, Bliwise DL. Genetic and environmental influences in sleep-disordered breathing in older male twins. Sleep 2004; 27: 917-922.

19 Monahan KJ, Larkin EK, Rosen CL, Graham G, Redline S. Utility of noninvasive pharyngometry in epidemiologic studies of childhood sleep-disordered breathing. Am J Respir Crit Care Med 2002; 165: 1499-1503.

20 Martin SE, Mathur R, Marshall I, Douglas NJ. The effect of age, sex, obesity and posture on upper airway size. Eur Respir J 1997; 10: 2087-2090. 